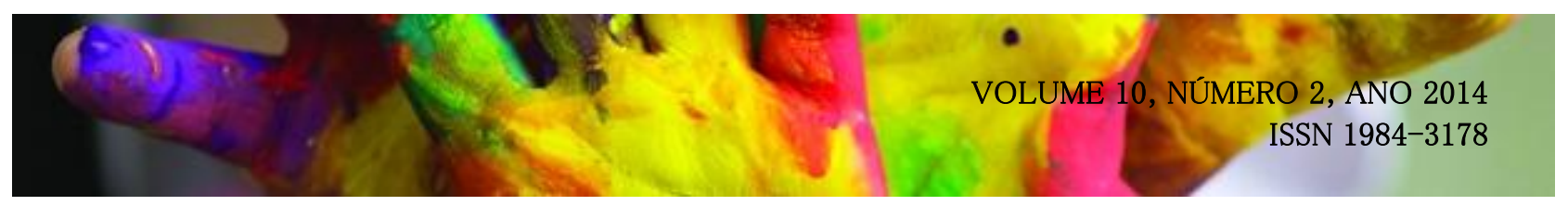

\title{
AÇÕES PEDAGÓGICAS PARA INCLUSÃO DE ALUNO COM TRANSTORNO DO ESPECTRO AUTISTA NUMA ESCOLA DE MÚSICA DE SÃO PAULO: RELATO DE CASO
}

\author{
DOI: http://dx.doi.org/10.5965/198431781022014138
}

Viviane dos Santos Louro ${ }^{1}$

\section{RESUMO}

O Transtorno do Espectro Autista (TEA), como é denominado pelo DSM V é um quadro diagnóstico que atinge 1 a cada 200 pessoas e que gera características atípicas em relação ao comportamento, linguagem e socialização. As iniciativas em prol da inclusão de pessoas com TEA no contexto educacional, vem crescendo sensivelmente e por esse motivo, o contexto musical não pode ficar à parte dessas discussões, visto que a música faz parte do leque de conhecimento de todas as culturas. Portanto, este artigo tem por objetivo apontar as ações pedagógicas utilizadas para inclusão de um adolescente com Transtorno do Espectro Autista (TEA) numa tradicional escola de música de São Paulo, entre os anos de 2006 a 2013. Para tanto, foi realizado um relato de caso, baseado nos relatórios, documentos, laudos e avaliações arquivadas no prontuário do aluno na respectiva escola. Os resultados apontam nove ações pedagógicas específicas para que o aluno pudesse permanecer na escola dentro do contexto pedagógico musical comum a todos.

Palavras chaves: TEA; educação musical; música; educação inclusiva; ações pedagógicas.

\begin{abstract}
The Autistic Spectrum Disorder ( ASD ), as it is called by the DSM V diagnosis is a framework that strikes 1 in every 200 people and generates atypical characteristics in relation to behavior, language and socialization. Initiatives to promote the inclusion of people with ASD in educational settings

has been growing significantly and therefore, the musical context can not be the part of those discussions, since the music is part of the range of knowledge of all cultures. Therefore, this article aims to point out the pedagogical practices used for inclusion of a teenager with Autism Spectrum

Disorder ( ASD ) in a traditional music school of São Paulo, between the years 2006-2013 . Therefore, we performed a case report, based on the reports, documents , reports and evaluations filed in the records of the student in their school. The results point nine pedagogical actions specific to that student could stay in school within the music pedagogical context common to all. Keywords: ASD, music education, music; inclusive education; pedagogical actions.
\end{abstract}

\footnotetext{
1 Doutoranda; Universidade Federal de São Paulo / Escola Paulista de Medicina. Disciplina de Neurologia Experimental / Departamento de Neurologia e Neurocirurgia. Rua Pedro de Toledo, 669 - Edifício de Pesquisa II (andares: primeiro e segundo). Vila Mariana, São Paulo - SP, Brasil
} 


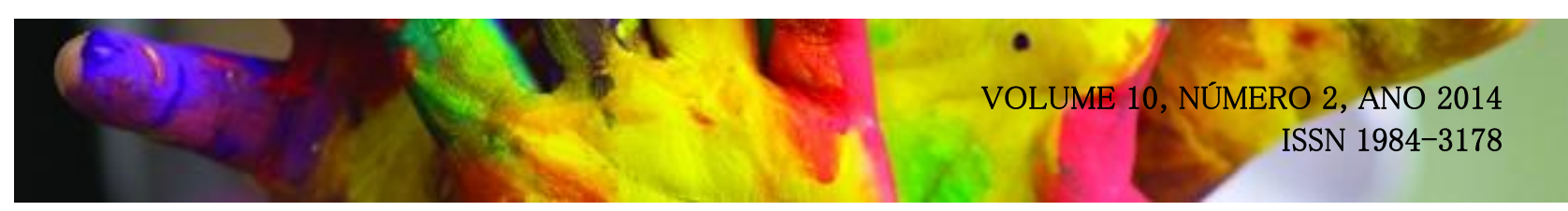

\section{O TRANSTORNO DO ESPECTRO AUTISTA (TEA)}

O autismo foi descrito pela primeira vez pelo psiquiatra americano Kanner em 1943, a partir do estudo com 11 crianças que possuíam características semelhantes entre si em relação a comportamentos atípicos (Kanner apud Lampreia, 2007)². Apesar dessa descrição inicial, foi somente no início dos anos 60 que as pesquisas sobre esse quadro evoluíram, pois até então, acreditavam que as características típicas dessa patologia eram advindas de sérios problemas emocionais e somente em poucos casos isolados (Pereira, 1999).

Em 1976, a Dr $^{\mathrm{a}}$ Lorna Wing, resumiu as características desse quadro diagnóstico no comprometimento de 3 áreas específicas: imaginação, socialização e comunicação. Também foi ela que deu os primeiros passos para o conceito de um espectro autista, ou seja, uma constelação variável de dificuldades dentro das 3 áreas citadas (Pinheiro e Camargo Júnior, 2005)

Outra característica enfatizada por Wing, conforme coloca Leal (1996, p. 34), foram os movimentos repetitivos, chamados de estereotipias (quando são somente motoras) e ecolalias (quando são referentes a repetição da fala). Toda sua teoria ficou conhecida como "Tríade de Wing" e que em suma, alega que independente do grau do autismo, todos terão comprometimentos na socialização, comunicação e imaginação.

De acordo com Klin (2006, p. 97), esse grupo de condições afeta aproximadamente 1 em cada 200 indivíduos, sendo a maior parte meninos e seus sintomas típicos devem aparecer antes dos 36 meses.

Desde que foi relatado pela primeira vez, os critérios diagnósticos têm se modificado nas diferentes edições dos manuais de classificação dos transtornos mentais, tanto da Organização Mundial da Saúde (2003), quanto da Associação Americana de Psiquiatria (Manual Diagnóstico e Estatístico dos Transtornos Mentais - DSM) (Teixeira et al, 2010).

Pelo DSM-IV (APA, 2002), ainda amplamente utilizado, o autismo é classificado como um transtorno global do desenvolvimento (TGD), que se caracteriza pelo desenvolvimento acentuadamente atípico na interação social e comunicação e pela presença de um repertório marcadamente restrito de atividades e interesses, além do uso constante de estereotipias 


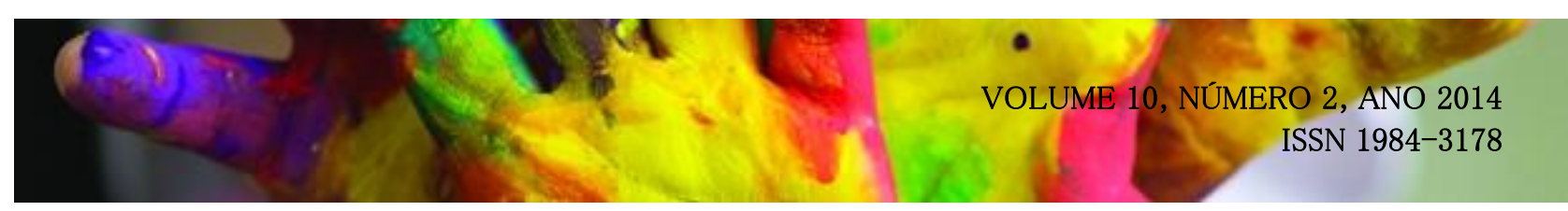

(movimento e fala repetitiva). Já o DSM-V, ainda recente, propõe a substituição do termo Transtorno Global do Desenvolvimento para Transtorno do Espectro Autista (TEA) e compila em 3 categorias (grave, moderado e leve) o que antes eram os diversos tipos de autismo (espectro autista; síndrome de asperger; autismo de auto funcionamento, transtorno invasivo do desenvolvimento sem outras especificações -TID SOE - dentre outros) (APA, 2013). ${ }^{3}$

Outra característica muito comum no autismo é um prejuízo na Teoria da Mente. Consoante Caixeta e Caixeta (2005, p.7) a "Teoria da mente é o nome que se dá à maneira como sentimos e entendemos a mente dos outros. [...] Ela é fundamental para compreensão do processo pelo qual entendemos as próprias emoções e emoções dos outros". Pinheiro e Camargo Júnior (2005, p. 65) completam dizendo que a "Teoria da Mente é a capacidade de atribuir estados mentais (crenças, desejos, conhecimentos e pensamentos) a outras pessoas e predizer comportamento das mesmas em função destas atribuições".

Baron-Cohen (1991, p. 422), afirma que a habilidade de atenção compartilhada está ausente ou prejudicada em algumas crianças autistas. $\mathrm{O}$ sistema de atenção compartilhada está diretamente ligado ao mecanismo do olhar, uma vez que o compartilhamento da atenção passa inevitavelmente pelo olhar. O que faz com que essa atenção seja compartilhada através do olhar é justamente a relação emocional entre mãe e filho. O que promove o desenvolvimento da TM é a relação com o outro, principalmente com a mãe no diálogo tônico-afetivo e posteriormente, essa relação é ampliada para as outras pessoas e para o mundo em geral. Todos os estímulos produzidos pelo toque, voz, cheiro, visão, dentre outros, precisam ser integrados em um todo significante, que com o tempo, são nomeamos de forma intencional e emocional como amor, carinho, conforto, etc (Fonseca, 2007).

O autista tem a tendência de avaliar a intencionalidade como uma cadeia de engrenagens mecânicas, não percebendo o emocional por trás da intenção, ou seja, eles não conseguem integrar facilmente os estímulos sensoriais e dar significado intencional, emocional à eles. Sendo assim, há uma falha na Teoria da Mente, pois é ela que justamente permite a integração sensório-emocional. Para conseguirmos compreender o mundo ao nosso redor e aprender conteúdos complexos, o indivíduo tem de estar munido de noções sobre a intencionalidade do outro e sobre o mundo afetivo

\footnotetext{
3 Neste artigo será utilizado o termo TEA, proposto pelo DSM V.
} 


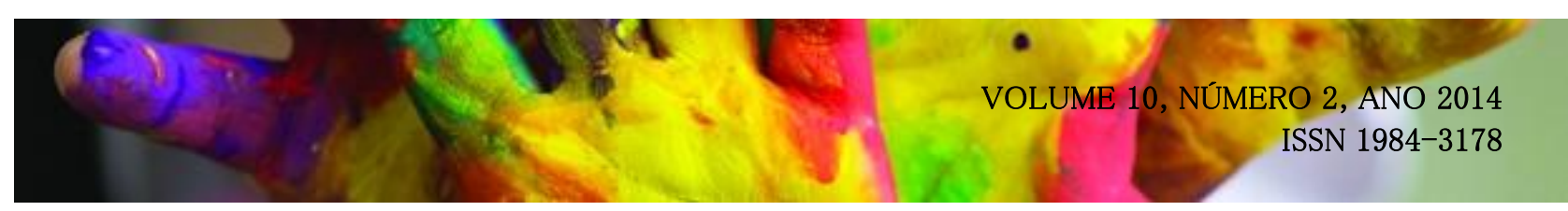

interno. Os indivíduos com TEA possuem dificuldade em aprender as coisas como uma junção de experiências (gestalt), pois suas mentes fragmentam o que percebem do meio e se apegam a detalhes, não conseguindo integra-los dar um sentido de todo. Essa é uma das explicações do motivo de se prenderem de forma obsessiva a sistematizações, rotinas e temas específicos (Caixeta \& Caixeta, 2005).

Até o presente momento, o autismo não tem uma cura, mas há diversos tratamentos e possibilidade de melhora desse quadro. Quanto mais cedo o tratamento começar, melhor o prognóstico. Isto implica tratamento psicoterapêutico, educacional e social (Bosa, 2006).

\section{Aprendizagem musical, TEA e inclusão}

Além das típicas características do TEA, como isolamento social, utilização de estereotipias, atraso de linguagem e prejuízo na Teoria da Mente, em alguns casos, é comum o desenvolvimento de habilidades específicas, por vezes surpreendentes, sendo a musical, presente em muitos dos casos. Só para citar um exemplo, temos Derek Pavacini ${ }^{4}$ (que além de autista é cego) e é atualmente um dos grandes expoentes da música popular e erudita nos EUA.

As pesquisas na área de música e autismo vem crescendo sensivelmente. Dentre elas, podemos recortar algumas, tais como: Barros (2010) que relata um caso de intervenção musical em uma criança com TEA numa escola regular; Wigram (2006), Padilha (2008) e Kafies et al. (2008) que descrevem trabalhos musicoterapêuticos com grupos de pessoas com esse quadro diagnóstico; Mottron et al. (2000) que comparou as habilidades auditivas musicais de um grupo de pessoas dentro do espectro autista com um grupo controle de pessoas dentro do desenvolvimento considerado normal; Lai (2012) que mapeou diferenças neurológicas entre a percepção da fala e dos sons em crianças com TEA; Dias (2012) que relata um caso bem sucedido de inclusão musical de aluno com TEA grau leve; Machado (2007) que propõe uma intervenção musical para desenvolvimento da comunicação de um grupo de crianças com autismo.

Devido essa propensão musical presente em alguns casos, a música é utilizada de forma enfática no tratamento dessas pessoas. Consoante Padilha (2008, p. 104), a música é de grande

\footnotetext{
4 www.sonustech.com/pavacini/
} 


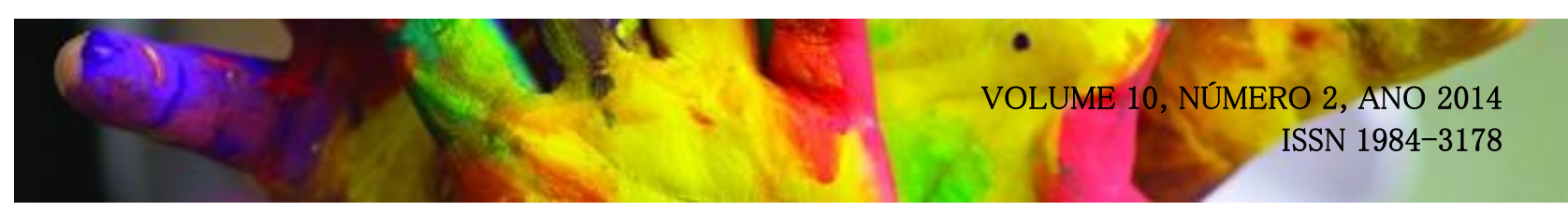

utilidade para crianças com autismo, pois as ajuda a serem mais espontâneas quanto à comunicação, diminuindo o isolamento e a ecolalia ${ }^{5}$. Além disso, a música colabora na diminuição das dificuldades sensoriais e na integração social quando é utilizada em atividades em grupos (Miller e Eller-miller, 1989) e devido sua propriedade não-verbal, é uma ferramenta eficaz para o desenvolvimento da linguagem (Wigram e Gold, 2006).

Mas, além de métodos terapêuticos, pode-se pensar em contribuir com o desenvolvimento de habilidades sociais e Teoria da Mente, em autistas, também a partir da aprendizagem musical, pois os fatores emocionais são fundamentais para a existência e aquisição do conteúdo musical (Sloboda, 1985, p. 2). Além disso, o vínculo afetivo travado num processo de aprendizagem entre professor e aluno, e entre os alunos do grupo, são de fundamental importância para o estímulo cognitivo. Delfrate (2009, p. 331) coloca que a partir do momento em que se estabelecem interações significativas entre terapeuta e paciente a linguagem e postura da criança com autismo, mudam significativamente para algo mais funcional e com sentido. Isso certamente pode ser transposto para a relação pedagógica.

Além da questão afetiva, a música está ligada à questões cognitivas. Levtin (2008, p.129) comenta que o cérebro representa a música a partir de códigos mentais ou neurais e Beyer (1988, p. 86) coloca que "ao se elaborar situações de educação musical, o discurso musical terá de ser desmontado, examinado e novamente reconstruído parte por parte", de forma gradativa e crescente de dificuldade, assim como na linguagem falada. Sendo assim, o exercício mental necessário para compreensão da música vai de encontro as dificuldades apresentadas no autismo no que se refere a simbolização, abstração e generalização. É por esses motivos que a aprendizagem musical pode contribuir no desenvolvimento da socialização, cognição e Teoria da Mente, em pessoas com autismo.

Louro (2014, p. 349) coloca que através do incentivo de pequenas tomadas de decisões no ato de improvisar musicalmente em jogos coletivos, gradativamente, o aluno com TEA pode começar a perceber o contexto em que está inserido e com isso, desenvolver a habilidade de compreender o universo ao seu redor e de criar coisas cada vez mais complexas. A autora pontua:

\footnotetext{
${ }^{5}$ Falas repetitivas empregadas sem contexto, também chamada de estereotipia vocal ou da fala (APA, 2002).
} 


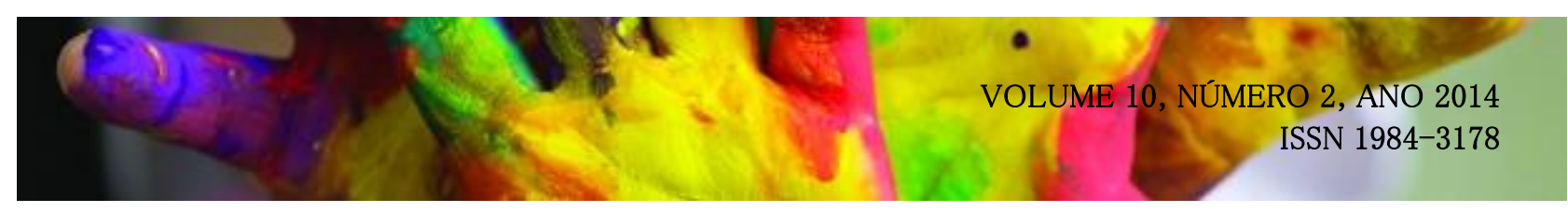

Para decidir, por exemplo, que som ou ritmo fazer, dentro de uma atividade de improvisação coletiva, a pessoa precisa primeiramente observar o que os outros estão fazendo. Num segundo momento, necessita comparar o que todos estão executando para chegar à conclusão se há um ritmo, som ou ideia principal que conduz a música improvisada coletivamente. A terceira fase é criar uma "imagem interna" do som ou ritmo que pretende fazer e logo em seguida, observar pela escuta interna se o que está imaginando está adequado musicalmente com o conjunto. Para saber se dará certo o que pretende improvisar, o individuo precisa se remeter mentalmente a um futuro imediato, imaginando o seu som juntamente com os demais. Só depois desse ato interno poderá decidir se vai ou não executar aquele som ou ritmo imaginado. Sendo assim, os jogos musicais podem contribuir com o desenvolvimento da TM (LOURO, 2014, P. 349).

Por isso, é importante pensarmos em capacitar melhor os professores de música, para que esses possam lidar de forma mais adequada com o autismo no contexto pedagógico, uma vez que esses alunos podem se desenvolver musicalmente muito bem e com isso, melhorarem outras questões importantes para seu desenvolvimento global.

De acordo com Camargo e Bosa (2009), as iniciativas em relação a inclusão de pessoas com TEA no contexto escolar vem crescendo significativamente, embora ainda sejam poucas diante das necessidades, pois a inclusão implica num diálogo constante entre muitas áreas e pessoas: família, escola, professores, médicos, terapeutas e a própria pessoa com deficiência (Louro, 2012).

Mesmo com tais dificuldades, faz-se necessário se pensar na inclusão desses indivíduos também na área pedagógica musical. Nesse sentido, uma escola de música de São Paulo, desenvolve um trabalho diferenciado no que tange a inclusão de alunos com deficiências diversas, dentre elas, o TEA. A escola referida fica em São Caetano do Sul, na Grande ABC, em São Paulo e é uma tradicional e reconhecida escola de artes (música, teatro, artes visuais e dança), de nível técnico e profissionalizante que possui em seu quadro de atividades um programa específico para inclusão denominado de Programa de Apoio Pedagógico e Inclusão (PAPI) (Soares, 2012).

Esse programa, criado em 2007, é coordenado por duas professoras da escola e atende somente ao curso de música, que é o com maior número de alunos e com maior demanda de pessoas com deficiências. Desde sua criação, já atendeu mais de 50 alunos dentre pessoas com deficiência intelectual, TEA, problemas de aprendizagem, deficiência física, problemas de processamento auditivo, transtornos psiquiátricos e distúrbios psicomotores (Soares, 2012).

Portanto, a partir do relato de um caso, o artigo tem por objetivo apontar as ações pedagógicas utilizadas para a inclusão de um adolescente com Transtorno do Espectro Autista 


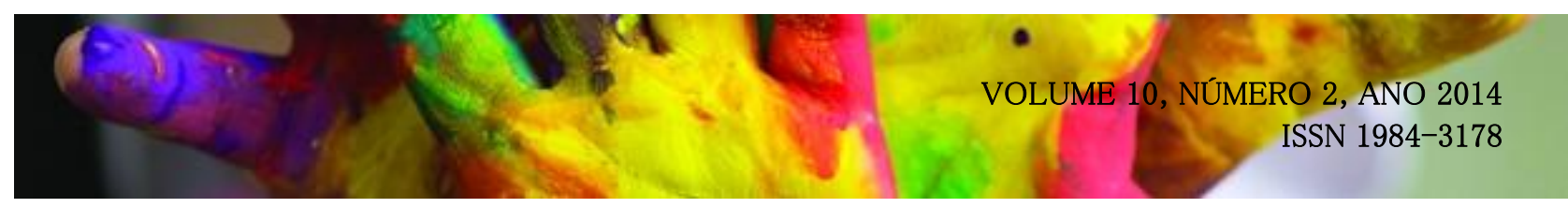

(TEA) no curso de música da escola pelo Programa de Apoio Pedagógico e Inclusão (PAPI). Com isso, pretende-se ampliar as discussões na área da educação musical inclusiva para que outras pesquisas ou iniciativas semelhantes à descrita neste artigo, possam se desenvolver, pois a literatura carece de mais pesquisa nessa temática.

\section{Método}

Para o embasamento teórico e discussão, foram realizadas pesquisas nas bases de dados Pubmed, Lilacs e Scielo, com as palavras chaves: música, autismo; TEA; inclusão ${ }^{6}$. Além disso, utilizou-se o banco de dados das revistas e dos anais da Associação Brasileira de Educação Musical (ABEM) e das bibliotecas das faculdades de música da USP e UNESP. Foram consultados também, livros representativos na área da educação musical, autismo e inclusão e as descrições clínicas e diretrizes diagnósticas da "Classificação de Transtornos Mentais e de Comportamentos da CID-10" e do "Manual Diagnóstico e Estatístico dos Transtornos Mentais-DSM".

Para o relato de caso foram resgatados os relatórios, laudos, avaliações e registros de reuniões sobre o aluno em questão entre os anos de 2006 à 2013, contidos no prontuário do aluno na escola em questão. ${ }^{7}$

\section{SOBRE A ESCOLA DE MÚSICA E O PROGRAMA DE APOIO PEDAGÓGICO E INCLUSÃO (PAPI)}

A escola no qual ocorreu o processo inclusivo é situada em São Caetano do Sul, em São Paulo. Trata-se de uma escola que promove cursos livres e profissionalizantes em música e teatro e cursos livres em artes visuais e dança. A escola é muito tradicional no ensino musical, tendo formado músicos de renomes no cenário nacional.

O curso de música é dividido da seguinte forma:

- 4-11 anos de idade - musicalização infantil (dividida em níveis pela faixa etária)

- 12 anos de idade em diante - curso de formação musical, dividido em:

6 meses de curso básico

Em português e inglês.

A estrutura desse artigo está baseada no que propõe Kienle e Kiene (2012) para relatos de caso. 


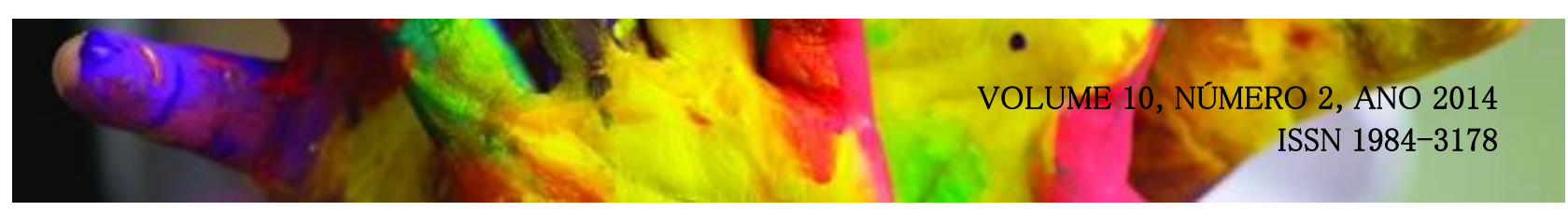

3 anos de curso livre

2 anos de curso profissionalizante

A escola conta com aulas de todos os instrumentos sinfônicos (de orquestra), além de piano erudito e popular, canto lírico, violão erudito e popular e bateria. Além disso, possui vários organismos formados por alunos, como parte da grade curricular, tais como orquestra sinfônica, grupos de câmara, coral, grupos de música popular (chamado também de combos) e grupo de percussão.

O Programa de Apoio Pedagógico e Inclusão (PAPI) foi fundado em 2007 por duas professoras da escola que trabalham também com inclusão em outros contextos pedagógicos. A necessidade de tal programa aconteceu devido ao aumento da procura de alunos com deficiências, problemas de aprendizagem e pessoas da terceira idade, para o curso de música.

O programa conta com várias ações, dentre elas:

- Mapear as dificuldades no que tange a aprendizagem musical, de alunos da escola de música que apresentem ou não laudo;

- Colaborar na formação dos professores e planejamento pedagógico para atuar com os alunos do programa;

- Capacitar monitores e estagiários para acompanharem os alunos do atendidos pelo PAPI;

- Encaminhar para especialistas da área de saúde, alunos que não apresentam laudo, mas que possuem quadros complexos do ponto de vista da aprendizagem;

- Atuar na sensibilização das famílias dos alunos com deficiência no que se refere a busca de tratamentos e terapias fora do contexto escolar;

- Manter diálogo próximo com os profissionais da área de saúde que atendem os alunos do programa, fora da instituição, para melhorar o planejamento pedagógico na escola de música;

- Oferecer aulas de apoio musical para os alunos atendidos no programa, em horário extra curricular. 


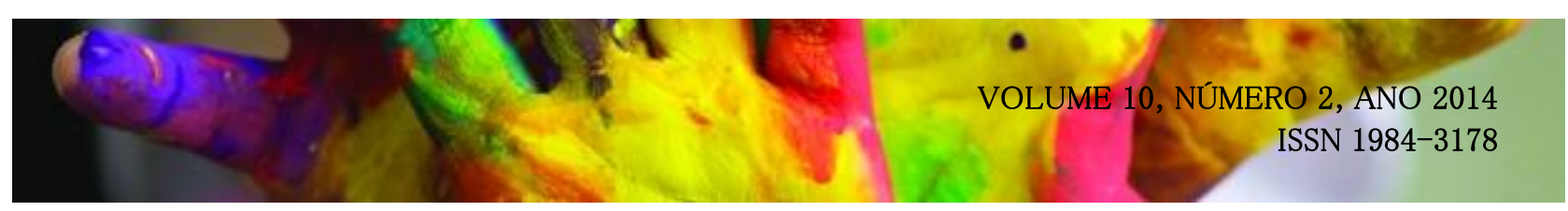

Para integrar o programa, o aluno precisa ter laudo médico confirmando alguma deficiência ou transtorno e apresentar dificuldade na aquisição do conhecimento musical. Se sua deficiência ou transtorno em nada interferir nas questões pedagógicas ou sociais, o aluno em questão não é atendido pelo programa. Outro público atendido, são aqueles alunos que não possuem laudo ou nenhuma dificuldade comprovada, mas que não conseguem avançar, por algum motivo, na aprendizagem musical. Nesses casos, para adentrar o programa a pessoa precisa ser indicada pelos professores, ter constantes notas vermelhas e histórico de repetência no curso de música.

A escola conta também com um sistema de cotas para aulas de instrumentos musicais, pois não são todos os alunos que conseguem vaga para estudar o instrumento. Qualquer pessoa que queira adentrar o curso de música, precisa passar por um processo seletivo, sendo que há menos vagas de instrumentos, do que interessados. Por isso, são selecionados, geralmente, os alunos que apresentam maiores condições de seguirem profissionalmente o estudo do instrumento. Mesmo os que não passam no teste instrumental, podem se matricular nas aulas coletivas de teoria e participar de alguns grupos da escola, como o coral, por exemplo. No caso do PAPI, há uma cota de vagas reservadas para alunos atendidos pelo programa, no qual o teste é diferenciado e eles não precisam competir com os demais alunos da escola.

O programa conta com monitores, que são alunos que se encontram em fases mais adiantadas na escola de música e recebem bolsa integral para acompanharem os alunos do programa nas aulas coletivas. Para ser monitor, o aluno precisa se cadastrar como interessado, ter no mínimo 18 anos de idade, ter boas notas em todas as disciplinas e perfil apropriado para trabalhar com pessoas (ser calmo, paciente, criativo e não ter preconceito em lidar com a diversidade). O objetivo do monitor é ajudar o professor a lidar com as condições diferenciadas de aprendizagem, como também, ajudar os alunos a estudarem e se organizarem com os materiais e compromissos da escola. O monitor é fundamental para o funcionamento do programa, pois ele age como "ponte" entre as professoras que coordenam o PAPI e os professores na sala de aula. Além de atuarem como porto seguro para os alunos com deficiências mais complexas.

No decorrer dos 7 anos de programa de apoio, já foram atendidos mais de 50 alunos, de todas as faixas etárias e das seguintes condições: autismo (TEA), deficiência intelectual, deficiência física, baixa visão, problemas psicomotores, distúrbios de aprendizagem, problemas psiquiátricos, 


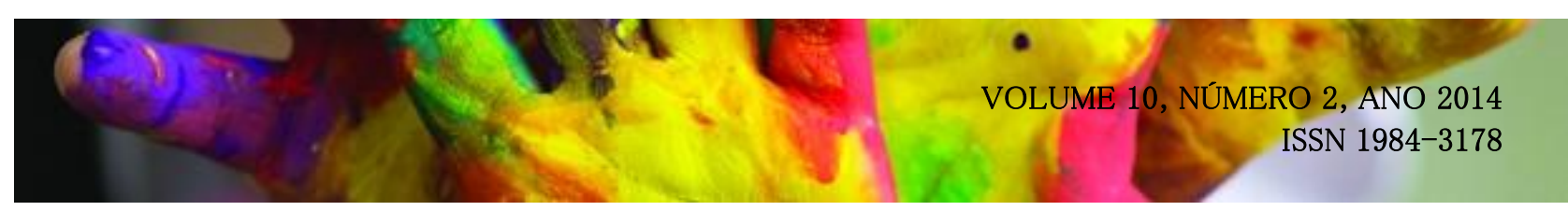

distúrbio do processamento auditivo central e pessoas com dificuldades na aprendizagem musical, sem especificação de deficiência ou distúrbio.

Os resultados tem sido satisfatórios: diminuição das reprovas e notas baixas; com a intervenção do programa, famílias começaram a aceitar melhor o diagnóstico de seus filhos, bem como, alguns tratamentos e terapias foram conseguidos em instituições de saúde importantes, gratuitamente, para alunos com menos possibilidades financeiras.

O PAPI tem contribuído também com a mudança de consciência entre os professores, que passaram a acreditar mais na importância da inclusão e da necessidade de se capacitarem para lidar com a diversidade. Além disso, alunos que foram monitores do programa, passaram a se especializar nesse assunto, buscando cursos na área, alguns deles, realizaram trabalhos científicos sobre o programa e sobre a experiência de acompanharem esses alunos, bem como, conseguiram empregos em outras escolas para também trabalharem com pessoas com deficiências.

\section{Relato de caso}

Augusto $^{8}$ tem atualmente 20 anos de idade, diagnóstico de TEA grau moderado; é alfabetizado e faz uso constante de estereotipias motoras (mexer os braços e pular). Ele consegue falar, mas se expressa verbalmente muito pouco, geralmente, só quando é solicitado e depois de muita insistência por parte de quem está conversando com ele. Seu diagnóstico foi feito ainda criança e ele frequentou muitas terapias durante toda sua vida. Porém, apesar de muita dificuldade na comunicação, interação social e cognição, demonstrou interesse por música desde a tenra idade. Por isso, seus pais o colocaram para estudar música numa escola perto de sua casa, ainda criança.

Augusto chegou à nossa escola no ano de 2004, aos 10 anos de idade, quando entrou no curso de musicalização infantil. Devido suas dificuldades dentro do contexto de aula, as professoras que criaram o PAPI, começaram a atuar com ele e a professora de musicalização, de forma indireta, até que, em 2007, o Programa de Apoio de fato se estruturou.

O curso de musicalização dessa escola tem por objetivo sensibilizar a escuta das crianças para a música, desenvolver a percepção auditiva e coordenação motora, ampliar o conteúdo e repertório cultural e proporcionar o contato com diversos instrumentos musicais. Geralmente, as

\footnotetext{
8 Nome fictício para preservar a identidade original do aluno.
} 


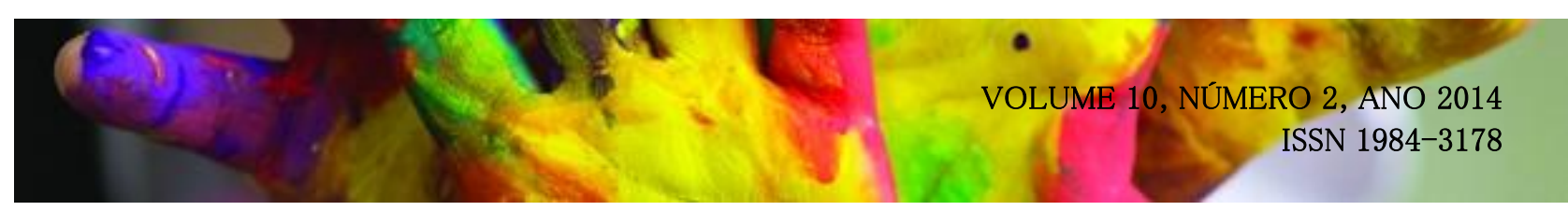

crianças tem duas aulas por semana, uma de jogos musicais e outra da orquestra infantil, onde tocam vários instrumentos e montam pequenos repertórios.

Logo que entrou, Augusto se mostrou bastante entusiasmado com as aulas, mas os professores se sentiram temerosos em trabalhar com ele, devido sua dificuldade de interação e comunicação. Por isso, as coordenadoras do PAPI propuseram ações formativas aos professores e colocaram um monitor em sala de aula para que as ajudassem nas aulas.

Augusto se desenvolveu bem na proposta da musicalização, mas devido suas dificuldades precisou refazer o semestre por duas vezes, para que pudesse compreender bem o conteúdo proposto. Quando fez 13 anos, Augusto passou para o curso básico, com duração de um semestre, com aulas semanais de 3 horas. O objetivo desse curso é promover conceitos fundamentais da teoria musical e preparar os alunos para o curso livre da escola. Nesse momento, as dificuldades se acentuaram, pois a aula, que antes tinha como proposta atividades lúdicas e jogos, passou a ser de cunho mais teórico, o que evidenciou as dificuldades cognitivas do aluno.

Por isso, o PAPI, além da monitoria, propôs aulas de apoio pedagógico, em horário extracurricular. Essas aulas aconteciam individualmente, uma vez por semana, com duração de uma hora e eram ministradas por uma das coordenadoras do programa. Essas aulas tinham por objetivo trabalhar as dificuldades específicas do aluno em relação à abstração, aquisição de conteúdo teórico musical e memória frente ao currículo estipulado nas aulas coletivas.

O aluno fez o curso básico duas vezes e quando completou 14 anos, passou para o curso livre da escola de música. O curso livre dura 6 semestres $^{9}$ e tem por objetivo aprofundar o conhecimento musical teórico. É composto por 4 disciplinas teóricas diferentes e as aulas ocorrem duas vezes por semana (duas disciplinas em cada encontro).

O curso livre é um curso muito concorrido, que prepara frequentemente os alunos para adentrarem ao curso profissionalizante da escola, bem como, para que os alunos prestem vestibulares para faculdades de música. Sendo assim, é um curso que exige muito dos alunos e tem alta carga horária. Nesse contexto, os desafios de inclusão para Augusto aumentaram sensivelmente e o PAPI propôs, além da monitoria e aulas de apoio, adaptações do conteúdo, dos materiais e das avaliações.

\footnotetext{
${ }^{9}$ Cada semestre é chamado de nível, portanto o curso livre compreende do nível 1 ao nível 6.
} 


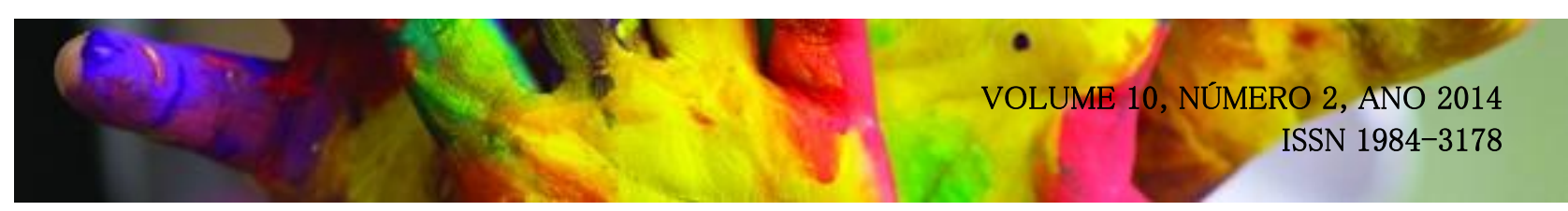

As coordenadoras do programa passaram a fazer reuniões formativas com mais frequência entre os professores e os monitores que acompanhavam Augusto. Além disso, foi eleito outro monitor (além dos monitores de sala), que ficou responsável por confeccionar materiais adaptados para serem utilizados nas aulas coletivas e nas aulas de apoio de Augusto.

Essas adaptações constavam de fichas que facilitavam a resposta do aluno em aula, visto que ele não se comunicava e demorava muito para escrever. Nessas fichas, continham nome das notas, figuras musicais, foto de instrumentos musicais, dentre outros conteúdos que eram abordados nas disciplinas. Também foram feitas adaptações nas partituras da aula de coral, uma vez que o aluno tinha dificuldade de compreender a letra da música. Foram feitas partituras, no qual, ao invés das letras, haviam figuras ilustrativas, escolhidas pelo próprio aluno junto com o monitor. Isso facilitava a compreensão do significado da letra. Além disso, as partituras continham somente os ritmos e notas musicais que o aluno conseguia ler e compreender e ao passo que Augusto ampliava seus conhecimentos, essas partituras eram modificadas e dificultadas.

As avaliações foram igualmente adaptadas, pois como seu currículo era reduzido frente aos demais, a avaliação precisava ser referente às suas possibilidades. Foram muitos os tipos de adaptações nas avaliações, dentre eles: exercícios com opções, no qual o aluno precisava somente assinalar a correta; enunciados com figuras para colaborar na compreensão da comanda; avaliações individuais, no qual Augusto tinha mais tempo para preencher os exercícios, dentre outras.

Além das adaptações de conteúdo e avaliação, o PAPI propôs duas ações diferenciadas: a possibilidade de dispensa de disciplina coletiva com substituição desta por aula individual e a possibilidade de cursar as disciplinas independentemente uma da outra.

Essas duas ações possibilitaram a permanência do aluno na escola, uma vez que ele fora dispensado de duas disciplinas (estruturação musical e rítmica ${ }^{10}$ ), devido a grande complexidade de abstração e raciocínio lógico que elas exigem. Ambas as disciplinas foram substituídas por aulas individuais adaptadas para suas possibilidades. Nas outras duas disciplinas o aluno continuou cursando com o grupo de alunos sem deficiência e com a permanência dos monitores em sala. Além

\footnotetext{
10 A aula de estruturação se destina a oferecer todo conteúdo de teoria musical, tais como os símbolos que compõe a escrita musical e princípios de composição musical. A aula de rítmica trabalha muito a questão matemática da escrita musical, além de raciocínio lógico e as figuras que compõe a escrita da partitura.
} 


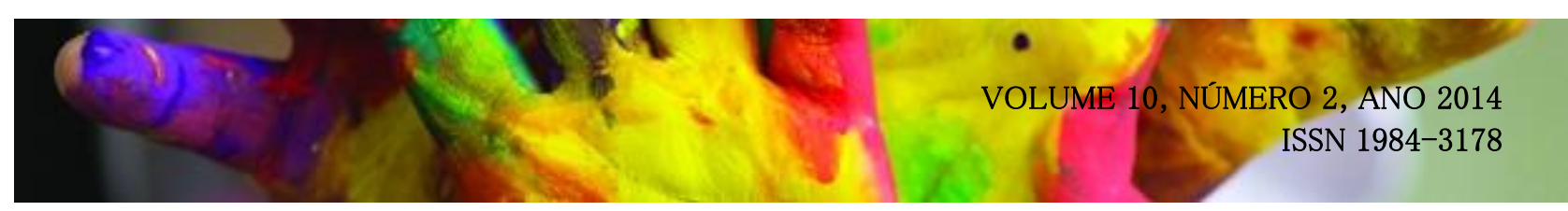

disso, a escola abriu a exceção de deixar o aluno cursar em um nível, a disciplina em que ia melhor e refazer a outra disciplina que tinha mais dificuldade, no nível anterior ${ }^{11}$. Com todas essas ações, o aluno conseguiu dar continuidade aos estudos na escola e avançar seus conhecimentos musicais.

Em 2012 surgiu um novo desafio: o PAPI propôs que o aluno começasse a cursar aula de algum instrumento musical. Como já mencionado anteriormente, é grande a demanda de alunos que cursam somente as aulas de teoria, pois há poucas vagas de instrumentos. Para poder fazer aula de um instrumento, a pessoa precisa passar por um processo seletivo muito concorrido. Para solucionar esse problema a escola decidiu em conjunto com o PAPI, oferecer uma cota de vagas para o Programa de Inclusão, assim, esses alunos não concorreriam com os demais. Então, Augusto entrou pela cota nas aulas de piano com uma professora que resolveu assumir o desafio. $\mathrm{O}$ aluno foi muito bem sucedido nessas aulas e atualmente vem se destacando pelo seu desempenho e é um dos alunos mais estudiosos dessa professora.

Mas para as aulas de piano o aluno também precisou (e ainda precisa) de algumas adaptações. A professora utiliza comandas simples e exemplos concretos para que o aluno compreenda o que precisa fazer; não usa metáforas para explicar questões referentes à interpretação das músicas; grava as aulas e assiste com o aluno para que ele perceba seu comportamento e compreenda as mudanças que precisa realizar na hora de tocar; utiliza cores nas partituras para que ele compreenda algumas nuances da interpretação pianística; anota passo a passo o que deve estudar em casa, com cronograma sistemático de atividades diárias frente ao instrumento.

Atualmente, o PAPI está em negociação com a fonoaudióloga que atende Augusto, para que seja confeccionada uma prancha de comunicação para facilitar o diálogo entre ele e a professora de piano. Augusto continua dispensado de algumas matérias teóricas coletivas, as cursando de forma substitutiva, individualmente, mas, em outras, permanece com o grupo.

\section{Discussão}

De acordo com Camargo e Bosa (2009, p. 79) para se trabalhar com o TEA é necessário um conjunto de medidas, dentre elas, a qualificação dos professores e apoio especializado. Baseado

11 Esse tipo de ação não é permitido na escola. Quando um aluno reprova somente uma disciplina, precisa refazer todas. 


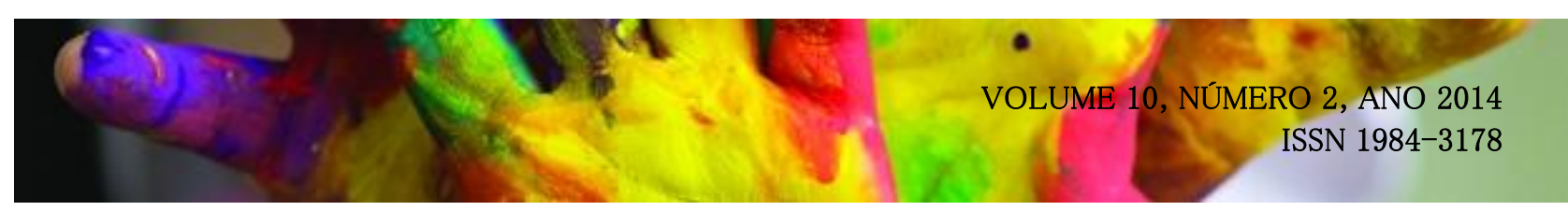

nisso, o PAPI, além de realizar ações pedagógicas específicas, tais como, adaptações de currículo, materiais e avaliações, visa também, capacitar professores e monitores através de reuniões e palestras formativas. Sendo assim, criam uma rede de pessoas e ações em torno de um único objetivo: oferecer uma educação musical de qualidade dentro das possibilidades do aluno e da escola (Soares, 2012).

Para que seja possível uma inclusão significativa, as adaptações são essenciais, principalmente no caso de pessoas com TEA que, geralmente tem dificuldade nas questões de abstração, raciocínio lógico e desenvolvimento da Teoria da Mente, ou seja, na capacidade de criar hipóteses, perceber o contexto ao seu redor e imaginar o que os outros estão sentindo e pensando, elementos essenciais para interação social e compreensão de conteúdos elaborados (Ottoni, 2005).

Por esse motivo, o uso de pistas visuais colaboram sensivelmente na aquisição do conteúdo, seja ele qual for, pois incentiva a visualização de elementos simbólicos. Como coloca Soares (2008, p. 1440) "o mundo das imagens traz uma significativa contribuição na mediação do autista com o mundo. A arte tem neste universo imagético um grande aliado. No uso da imagem como instrumentos mediadores do conhecimento, podemos observar resultados significativos".

Além do uso de imagens, é importante saber perceber as respostas "não verbais" do aluno com TEA. Lampreia (2007, p. 210) comenta sobre a importância de seguir o foco de atenção do aluno com autismo, oferecer-lhe escolhas e pistas e reconhecer as formas não convencionais de suas respostas. Por isso, o PAPI promove ações formativas para professores e monitores, que possibilitam que todos compreendam a importância do uso adequado das adaptações e percebam as nuances do comportamento autístico. Com isso, todos ficam mais cientes de como elaborar uma comanda adequada na hora dos exercícios e se tornam mais habilitados a perceber outros tipos de respostas dada pelo aluno, podendo assim, agir de forma adequada diante das características e possibilidades de Augusto, sem assistencialismo nem piedade.

É importante ressaltar também o papel da escola no processo de inclusão. Se a escola não é flexível para propostas alternativas, inviabiliza a permanência de alunos que se diferem do padrão. Nesse sentido, essa escola de música merece ser parabenizada pela iniciativa da criação de um programa específico que possibilita a inclusão e permanência de alunos com necessidades educativas diferenciadas. 


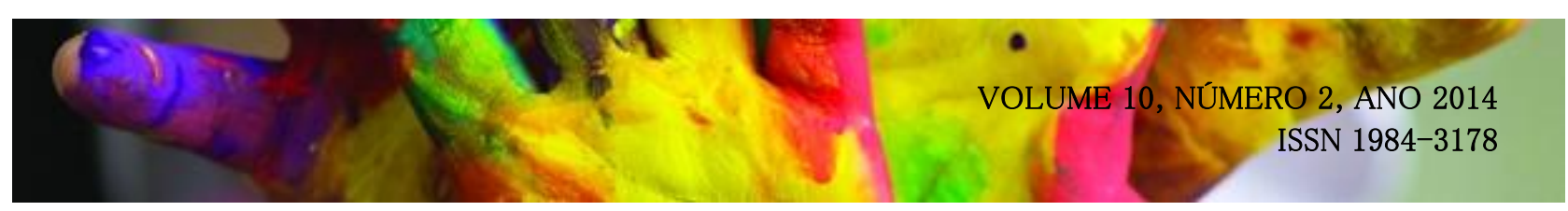

Castanho (1982, p. 34) coloca:

A arte envolve a construção de linguagem, onde interagem o racional e o sensível. Arte, portanto, é conhecimento, pois no fazer artístico estão presentes processos mentais de raciocínio, memória, imaginação, abstração, comparação, dedução, generalização, dedução, indução e esquematização.

Sendo assim, a música não pode ficar de fora das reflexões atuais acerca da inclusão pedagógica, pois, como afirma Pucetti $(2005$, p. 2) "a arte é uma das mais inquietantes e eloquentes produções do homem [...] que faz parte de nosso universo conceitual, ligado à visão de mundo e à expressão da humanidade".

Por último, não podemos deixar de lado uma breve discussão a respeito das conquistas pessoais do aluno em questão. Sugahara (2008: 24) afirma que a educação musical é importante "porque auxilia a percepção e estimula a memória e a inteligência, relacionando-se com habilidades linguísticas e lógico-matemáticas ao desenvolver procedimentos que ajudam o aluno a se reconhecer e se orientar melhor no mundo".

Sendo assim, a música pode contribuir sensivelmente com todas as questões neurocomportamentais de pessoas com TEA. Isso foi observado no caso descrito, pois Augusto, no início, possuía dificuldades significativas em todas as questões relacionadas à cognição e Teoria da Mente e com o passar dos anos e a partir das intervenções pedagógicas oferecidas pelo Programa da escola, Augusto melhorou em todos os aspectos: diminuiu as estereotipias, passou ter mais autonomia em sua vida diária, começou a entender conteúdos simbólicos do fazer musical, melhorou a coordenação motora com a prática do piano, se tornou mais sociável com desconhecidos.

Brito (2003, p. 45) completa dizendo que "a educação musical deve promover ao educando informações e vivências que visem enriquecer e ampliar o conhecimento, não apenas do ponto de vista musical, mas integralmente". Por esse motivo, faz-se necessário ampliar as discussões sobre a educação musical no contexto da educação básica e sua função na construção da cidadania. Da mesma forma, é importante aprofundar as reflexões a cerca da formação do professor de música, em geral, bem como, a função da aprendizagem musical no contexto das escolas de música e diante da performance artística. Por último, é imprescindível ampliarmos a consciência e debates sobre a inclusão dentro do contexto pedagógico musical, para que pessoas consideradas fora do padrão 


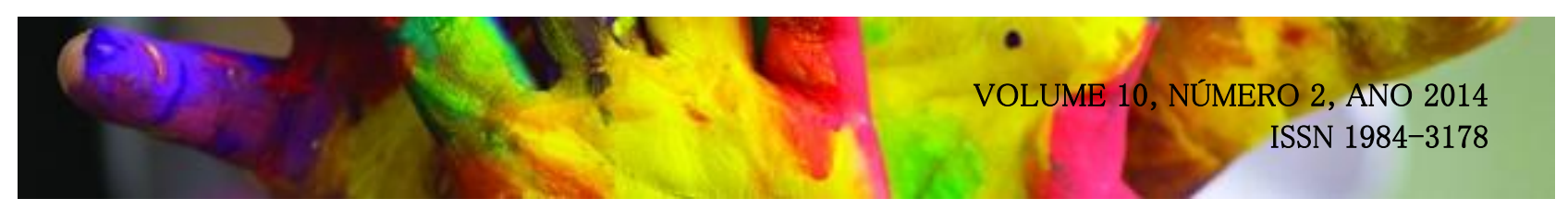

esperado, possam ter as mesmas chances que os demais, e usufruírem de uma aprendizagem musical de qualidade.

\section{CONCLUSÃO}

A partir do relato de caso, pode-se resumir que as ações pedagógicas utilizadas para a inclusão de aluno com TEA, através do Programa de Apoio Pedagógico e Inclusão, foram:

1. Monitoria em sala de aula (alunos mais adiantados da escola que acompanham o aluno com deficiência na sala de aula);

2. Adaptações de currículo, metodologia e materiais (partituras de coral com figuras para colaborar na compreensão da letra; partituras com menos notas e figuras musicais; utilização de cores nas partituras de piano para ajudar aluno compreender as nuances da interpretação; fichas com figuras e elementos musicais das aulas teóricas para colaborar na agilidade de resposta do aluno);

3. Adaptações de avaliações (avaliações com comandas em figuras; tempo ampliado para realização das provas; exercícios com alternativas);

4. Dispensa de disciplinas e substituição por aulas individuais;

5. Possibilidade de cursar disciplinas em níveis diferentes;

6. Criação de cotas para alunos com necessidades educativas especiais para as aulas de instrumento;

7. Aulas individuais de apoio em horário extracurricular (para trabalhar questões específicas da aprendizagem musical, como, raciocínio lógico, memória dentre outras necessidades do aluno);

8. Ações formativas com professores de música (reuniões e palestras);

9. Ações formativas com monitores de sala (reuniões e palestras);

10. Ações de apoio com familiares de alunos atendidos pelo programa.

Sendo assim, pode-se concluir que a inclusão de alunos com TEA é possível também na educação musical, desde que se façam algumas adaptações e promovam algumas ações diferenciadas, a partir de um trabalho em conjunto. 


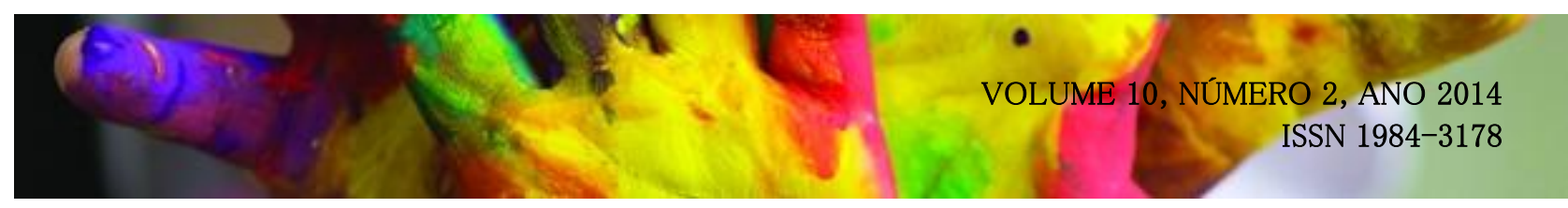

Além disso, conclui-se que uma pessoa com TEA pode ter bom rendimento musical e usufruir do conhecimento desta arte, como qualquer outra pessoa, e que este processo pode contribuir também com o desenvolvimento de questões relacionadas a cognição, Teoria da Mente e comportamento.

Por último, conclui-se que é necessário a ampliação das discussões na área musical no que tange a inclusão. Seria importante a ampliação de programas inclusivos como essa escola de música implantou, para que outras pessoas com autismo ou diferentes quadros diagnósticos possam usufruir da cultura musical ou de outras manifestações artísticas.

\section{REFERÊNCIAS}

AMERICAN PSYCHIATRIC ASSOCIATION. Diagnostic and statistic manual of mental Disorders. 4th ed. Washington: APA, 2002.

Autism spectrum disorder. Washington: APA, 2013. Disponível em $\measuredangle$ http://www.dsm5.org/Documents/Autism\%20Spectrum\%20Disorder\%20Fact\%20Sheet.pdf $>$ Acesso em 18 de Outubro de 2013.

BARON-COHEN, S. Autismo: Uma alteração cognitiva específica de "cegueira mental". Revista Portuguesa de Pedagogia, 24, p. 407-430, 1990.

BARROS, M. A Música como mediadora no desenvolvimento cognitivo em crianças com perturbações Autísticas: Intervenção junto de uma aluna com perturbações Autísticas. Tese de Mestrado apresentada à Escola Superior de Educação João de Deus, para a Obtenção do Grau de Mestre em Necessidades Educativas Especiais, no domínio Cognitivo, 2010.

BEYER, E. A abordagem cognitiva em música: uma crítica ao ensino da

música a partir da teoria de Piaget. Dissertação de mestrado, Universidade Federal do Rio Grande do Sul, Porto Alegre. 1988.

BOSA, C. Autismo: intervenções psicoeducacionais. Revista Brasileira de Psiquiatria, v. 28 (Supl. I), p. 47-53, 2006.

BRITO, Teca. A música na educação infantil: propostas para a formação integral da criança. São Paulo: Fundação Peirópolis, 2003.

CAIXETA, Marcelo; CAIXETA, Leonardo. A Teoria da mente: aspectos psicológicos, neurológicos, neuropsicobiológicos e psiquiátricos. Campinas, SP: Editora Átomo, 2005. 


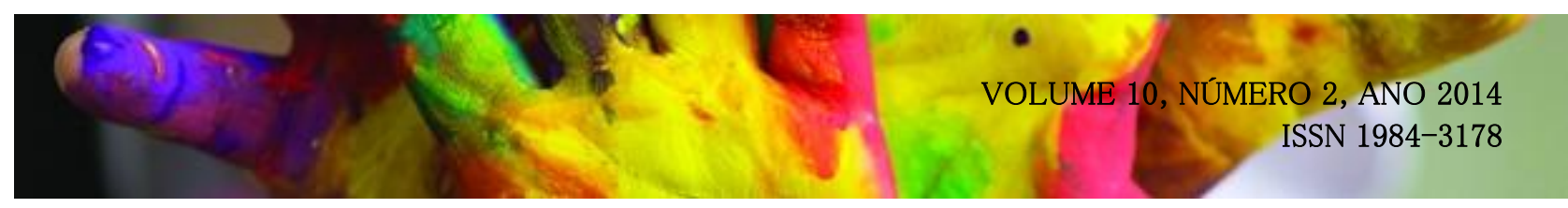

CASTANHO, M. Arte-Educação e intelectualidade da Arte. Dissertação (Mestrado) - Faculdade de Educação, Pontífice Universidade Católica/PUC - Campinas, SP, 1982.

DELFRATE, C., et al. Aquisição da linguagem em criança com autismo: um estudo de caso. Revista Psicologia em Estudo, vol 14, n. 2. pp. 321-331. Maringá: abril-junho, 2009.

CAMARGO, S. BOSA, C. Competência social, inclusão escolar e autismo: revisão crítica da literatura. Psicologia \& Sociedade, v. 21, n. 1, p. 65-74, 2009.

DIAS, S. O desenvolvimento de recursos musicais no cotidiano e a Síndrome de Asperger: um relato de experiência. Anais da IV semana de educação musical Ia-Unesp / VIII encontro regional sudeste da ABEM. São Paulo: Unesp, 2012.

FONSECA, Vitor. Cognição, neuropsicologia e aprendizagem: abordagem neuropsicológica e psicopedagógica. RJ: Vozes, 2007.

KAFIES. E. et al. Pacientes com deficiência intelectual e espectro autístico e o fazer musical. Anais do SIMCAM4 - IV Simpósio de Cognição e Artes Musicais, p. 1-4, 2008.

KIENLE, G. KIENE, H. Como escrever um relato de caso. Arte Médica Ampliada Ano XXXI, n.2, p. 34-37, 2011.

KLIN, A. Autismo e Síndrome de Asperger: uma visão geral. Revista Brasileira de Psiquiatria, v. 28 (Supl.1). São Paulo: May, 2006.

LAI. G. et al. Neural systems for speech and song in autism. Brain: a journal of neurology, v. 135, p. $961-975,2012$.

LAMPREIA, C. A perspectiva desenvolvimentista para a intervenção precoce no autismo. Estudos de Psicologia, v. 24, n. 1, p. 105-114. Campinas, 2007.

LEVITIN, D. Tu cerebro y la música. Tradução de José Manuel Álvarez. Barcelona: RBA Libros, 2008.

LOURO. V. Fundamentos da aprendizagem musical da pessoa com deficiência. São Paulo: Editora Som, 2012.

LOURO, V. Jogos musicais, transtorno do espectro autista e teoria da mente: um relato de experiência. Anais do X Simpósio de Cognição e Artes Musicais, pp. 345-353. Universidade Estadual de Campinas: UNICAMP, 2014.

MILLER, A. \& ELLER-MILLER, E. From ritual to repertoire: a cognitive-developmental systems approach with behavior-disordered children. New York: Wiley-Interscience, 1989.

LEAL, R. Emergências de significados e relação precoce. Revista Portuguesa de Psicopedagogia 


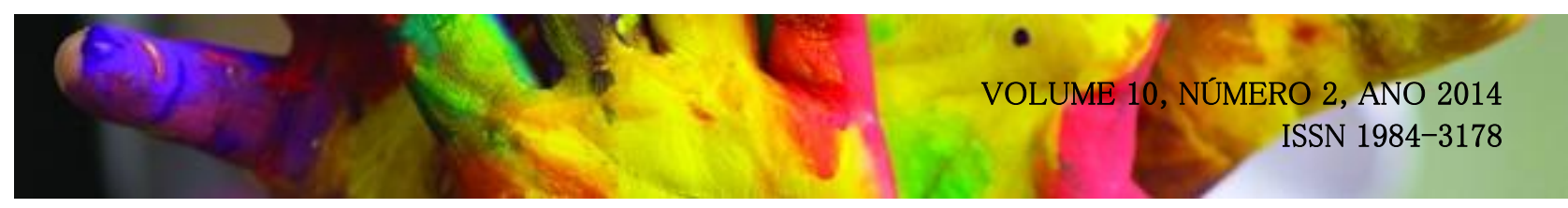

vol. 2, p. 19-44, 1996.

MACHADO, R. A voz da criança autista: o estímulo musical cantado como suporte à comunicação. Cadernos de Saúde, v. 8, n. 1, p. 65-73, 2007.

MOTTRON, L. Local and global processing of music in high-functioning persons with autism: beyond central coherence? Journal child psychology and psychiatry, v. 41, n. 8, p. 1057-1062, 2000.

ORGANIZAÇÃO MUNDIAL DE SAÚDE (OMS). Classificação de transtornos mentais e de comportamentos da CID-10: descrições clínicas e diretrizes diagnósticas. Porto Alegre: Artes Médicas, 1993.

OTTONI, E. et al. Teoria da Mente e compreensão da representação gráfica de conteúdos mentais. Revista Interação em Psicologia, v. 10, n. 2, p. 225-234, 2006.

PADILHA, M. A musicoterapia no tratamento de crianças com Perturbação no Espectro do Autismo. Dissertação para a obtenção do grau de Mestre em Medicina da Faculdade da Beira Interior. Portugal, 2008.

PEREIRA, E. Autismo: o significado como processo central. Lisboa: Secretariado de Reabilitação e Integração da Pessoa com Deficiência, 1999.

PINHEIRO, M. CAMARGO JÚNIOR. W. A Teoria da Mente e a aplicação nos portadores de transtorno invasivos do desenvolvimento. In CAMARGO JÚNIOR. Transtornos Invasivos do Desenvolvimento $-3^{\circ}$ milênio. Brasília: Secretaria especial dos direitos humanos, 2005.

PUCETTI. R. Articulando: arte, ensino e produção para uma educação especial. Revista Educação Especial, v. 25, p. 1-7, 2005.

SLOBODA, John. The Musical Mind: The Cognitive Psychology of Music. Reed. com correções. Oxford: Clarendon Press, 1989.

SOARES, R. O autismo, a arte e o ensino regular: uma convivência possível? Anais do $17^{\circ}$ Encontro Nacional da Associação Nacional de Pesquisadores em Artes Plásticas,

Panorama da Pesquisa em Artes Visuais, Florianópolis, p. 1437-1447, 2008.

SOARES, L. Programa de Apoio Pedagógico e inclusão: um estudo de caso. Revista da ABEM, Londrina. v. 20 n. 27, p. 55-64, 2012.

SUGAHARA, Leila. Música na escola: um estudo a partir da psicogenética Walloniana. Mestrado em educação: psicologia da educação. São Paulo: PUC, 2008. 


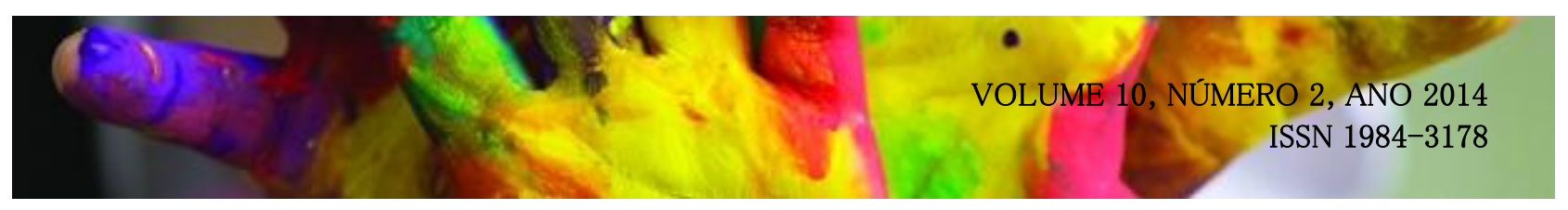

TEIXEIRA, M. et al. Literatura científica brasileira sobre transtornos do espectro autista. Revista Associação Médica Brasileira, v. 56, n.5, p. 607-14, 2010.

WIGRAM, T. GOLD, C. Music therapy in the assessment and treatment of autistic spectrum disorder: clinical application and research evidence. Faculty of Humanities, Institut for Musik of Musikterapi, Aalborg University, Aalborg, Denmark, 2006. 